Eur. J. Clin. Chem. Clin. Biochem.

Vol. 31, 1993, pp. 753-757

(C) 1993 Walter de Gruyter \& Co.

Berlin - New York

\title{
Interference of Metamizol (Dipyrone) on the Determination of Creatinine with the Kodak Dry Chemistry Slide Comparison with the Enzymatic Method from Boehringer
}

\author{
By M.-A. Bagnoud and J.-Ph. Reymond \\ Laboratoire de Chimie Clinique, Institut Central des Hôpitaux Valaisans, Sion, Suisse
}

(Received May 5/July 30, 1993)

Summary: In order to eliminate positive interferences that take place with the Jaffé technique, the Kodak Ektachem and Boehringer Mannheim Companies have chosen an enzymatic method for the determination of creatinine in serum and urine. Pathological and clinical samples often contain metabolites in elevated concentrations or exogenous compounds such as drugs or toxic compounds. We noticed that patients receiving metamizol-containing drugs showed unusually low values of creatinine when determined with an Ektachem analyser. We investigated the effect of the main metabolites of this prodrug on the creatinine enzymatic methods of Kodak and Boehringer. We concluded that methyl-amino-antipyrine, the active substance after administration of metamizol (prop. INN) was responsible for the interference, and that no reliable determination of creatinine could be performed with these methods in the serum of patients receiving this drug.

\section{Introduction}

Though registration of metamizol (dipyrone) has been cancelled in some countries (e.g. USA) due to rare cases of drug-induced agranulocytosis, this drug is a widely used analgesic in Switzerland and other European countries. The creatinine determinations of patients receiving "Novalgin $\left.{ }^{(}\right)$gave surprisingly low values with the dry slide enzymatic method of Kodak Ektachem. This first observation was later confirmed by Gascon et al. (1). The other enzymatic method from Boehringer gave similar interferences.

In order to study drug interference in chemical tests, the in vivo relevant drug and/or metabolites at their respective concentration after usual dosage are to be considered.

The metabolism of metamizol has been extensively studied (2). It has been shown that after iv. or oral administration of the drug in healthy humans, the hydrolysed compound, methyl-amino-antipyrine, is mainly detected. Metamizol can thus be considered as a prodrug, methyl-amino-antipyrine being the ac- tive substance. A $1 \mathrm{~g}$ iv. administration of metamizol in man, rapidly gives the hydrolysis product, methylamino-antipyrine (serum $c_{\max }=57 \mathrm{mg} / \mathrm{l}$ ) which undergoes either oxidation to formyl-amino-antipyrine $\left(c_{\max }=3 \mathrm{mg} / \mathrm{l}\right)$ or demethylation to amino-antipyrine $\left(c_{\max }=3 \mathrm{mg} / \mathrm{l}\right)$. Amino-antipyrine is further metabolised to acetyl-amino-antipyrine $\left(c_{\max }=3 \mathrm{mg} / \mathrm{l}\right)(3)$. Methyl-amino-antipyrine, formyl-amino-antipyrine, amino-antipyrine and acetyl-amino-antipyrine are present in the highest concentrations, and represent more than $70 \%$ of all the identified metabolites of metamizol in humans (4).

\section{Materials and Methods}

Samples and standards

4-Amino-antipyrine ( $p$-amino-phenazone) and antipyrine were from Fluka AG (Buchs, Switzerland). Methyl-amino-antipyrine, acetyl-amino-antipyrine and formyl-amino-antipyrine were synthesised by Hoechst and kindly offered for this study. Portions of $90 \mu \mathrm{l}$ of serum were spiked with $10 \mu$ l of solutions containing $500 \mathrm{mg} / \mathrm{l}$ of metamizol, methyl-amino-antipyrine or antipyrine, and $15 \mathrm{mg} / \mathrm{l}$ of formyl-amino-antipyrine, amino- 
antipyrine or acetyl-amino-antipyrine. Other portions of serum were spiked with $10 \mu \mathrm{l}$ of solutions containing $2 \mathrm{mmol} / \mathrm{l}$ of each compound. Serum was also spiked with pure water, so that the dilution procedure was taken into account for comparison purposes.

All specimens came from hospitalised patients, some with normal creatinine serum concentrations, other with high concentrations due to renal insufficiency.

\section{Creatinine determination with Ektachem slides}

This is our routinely used method. As two types of dry chemistry slides have been developed by the Kodak Ektachem Company, it is important to mention that only the "single slide methodology" was investigated and used for all experiments. The different steps of the methodology are represented on figure $1(5,6)$. The method was calibrated according to Kodak's recommendations using lyophilised calibrators and their "Supplementary Assigned Values" (7). The use of supplementary assigned values during calibration enables the analyser to report analyte concentrations which are as close as possible to the values that would be obtained with the reference method (this is "High Performance Liquid Chromatography" (8) in the case of creatinine). Controls for normal and pathological values (Kodatrol I and II, Eastman Kodak Company, Rochester, USA) were run each day, and series were rejected whenever one of the controls was out of the acceptable range. The analyser used was an Ektachem 500 .

\section{Creatinine determination with Boehringer kit}

The Boehringer Mannheim kit No. 836885 was used as another enzymatic method for comparison. Samples were run on a Cobas Mira (Hoffmann-La-Roche Ltd, Basel, Switzerland). Again normal and pathologic controls (Monitrol, Baxter Dade, Miami, USA)) were run each day to validate series of creatinine determinations. The reactions are the same as in the Kodak method, except that the last step employs a different dye (fig. 1).

\section{Creatinine determination with the Jaffé method}

The kinetic Jaffé method without deproteinisation was used to establish the creatinine concentrations of specimens that were supplemented with metamizol or metabolites. We used kit No. 0711152 from Roche, and a Cobas Mira as the analyser. The same controls from Baxter were used on each day.

The concentrations of creatinine determined with these three methods are different. The spiking of specimens induces a variation of the sample matrix known to give inaccurate results with dry slide chemistry. In order to visualise results independently of these phenomena, all results are presented as a relative (per cent) concentration of the water-supplemented specimen.

All determinations were assayed twice. The mean of both results was used for further calculations. With each method, intraassay variations are significantly lower $(\mathrm{CV}<3 \%)$ than the interference observed on spiked specimens.

\section{Results}

\section{Effect of each metabolite at $c_{\max }$}

Three sera, with a low, medium and high content of creatinine, were spiked with metamizol and each of the four main metabolites at their respective $c_{\max }$. Creatinine was determined with both enzymatic methods. Results can be seen in figure 2 . It is worth noting that spiking with metamiżol itself, from a Novalgin ${ }^{\circledR}$ ampoule, gives the same kind of interference as spiking with methyl-amino-antipyrine alone. This confirms the result of Itoh et al. (9) who showed that metamizol is rapidly hydrolysed in vitro, as well as in vivo. Figure 2 shows that after an usual iv. dose of metamizol, methyl-amino-antipyrine is the only me-<smiles>CN1CC(=O)NC1=N</smiles><smiles>CN(CC(=O)[O-])C(=N)N</smiles>

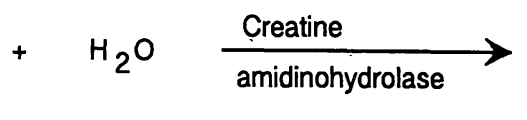<smiles>CNCC(=O)OCC(=O)O</smiles><smiles>CNCC(=O)[O-]</smiles><smiles>[18OH][18OH]</smiles><smiles>C[13CH2][13CH2][13CH2][13CH3]</smiles><smiles>O=C([O-])C[18O][Mg]</smiles>

Glycine
a) Kodak :
$\mathrm{H}_{2} \mathrm{O}_{2}$
$+\quad$ Leuko dye

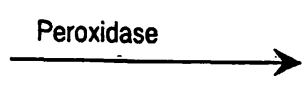
Coloured dye

b) Boehringer: $\mathrm{H}_{2} \mathrm{O}_{2}$

$+\quad \mathrm{TBHB}+\mathrm{PAP}$

Peroxidase

Quinone-iminé dye. $+2 \mathrm{H}_{2} \mathrm{O}+\mathrm{HBr}$

Fig. 1. Determination of creatinine according to Kodak and Boehringer methodologies (PAP $=$-amino-phenazone $=4$-aminoantipyrine $=\mathrm{AA} ; \mathrm{TBHB}=2,4,6$-tribromo-3-hydroxybenzoic acid). 


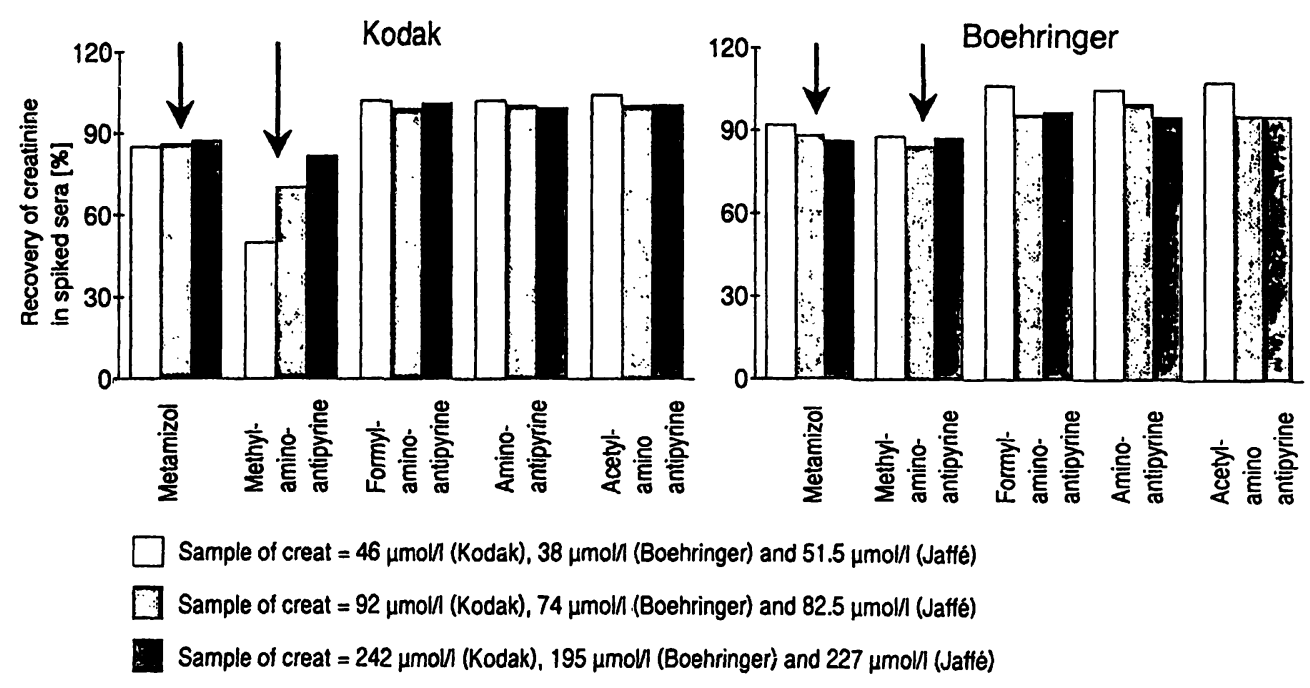

Fig. 2. Influence of metamizol and metabolites at $c_{\max }$ on the enzymatic determination of creatinine in serum with Kodak and Boehringer methods.

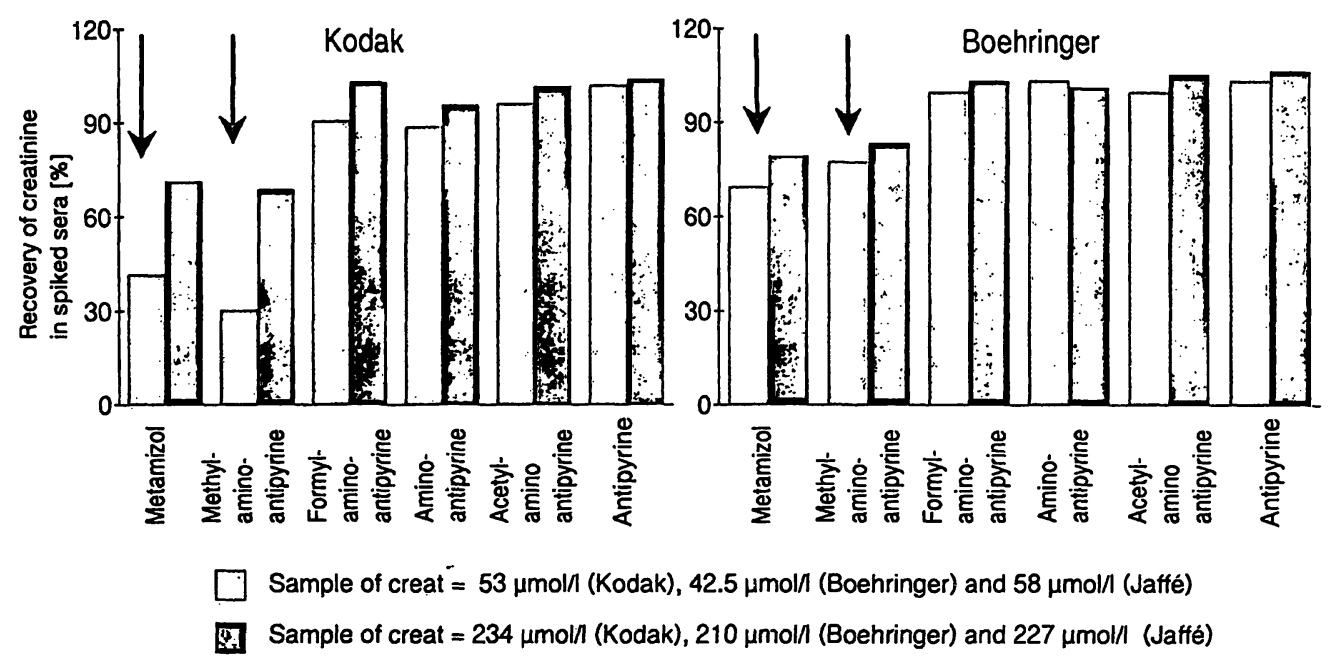

Fig. 3. Influence at equivalent molar concentration $(0.2 \mathrm{mmol} / \mathrm{l}$, equivalent for methyl-amino-antipyrine to $50 \mathrm{mg} / \mathrm{l})$ of metamizol and metabolites on the enzymatic determination of creatinine in serum with Kodak and Boehringer methods.

tabolite responsible for the decrease of the creatinine results. The other metabolites do not significantly interfere but this assay does not indicate whether the interference is structure related or not.

Effect of metabolites at the same concentrations

The $c_{\max }$ value of methyl-amino-antipyrine of $50 \mathrm{mg} / \mathrm{l}$ used for the preceding assays corresponds to 0.20 $\mathrm{mmol} / \mathrm{l}$; in vitro spiking with an equivalent molar concentration of metabolite was performed. Though it is not a natural metabolite of metamizol, antipyrine was added to these assays in order to enlarge the structure-related study. Results are found in figure 3. Here again the only interfering molecule is methylamino-antipyrine. Interference is greater in the Ektachem method than in the Boehringer. As Kodak Inc. does not communicate its procedure characteristics, it is difficult to assess if this is due to the different proportion of enzyme present in each test.
Importance of the interference with methylamino-antipyrine concentration

Different concentrations of methyl-amino-antipyrine were used to spike three sera, with low, medium and high concentrations of creatinine (fig. 4). The higher the concentration of methyl-amino-antipyrine, the stronger the interference. With the Ektachem slides the relative decrease of the creatinine results is greater with low concentrations than with high concentrations. This is not the case with the Boehringer method. As the enzymes used in both methods have the same origin, the explanation may be related to the different procedures rather than to the nature of the interference.

\section{Validation on a large series}

Fifty samples covering values of creatinine from 20 to $530 \mu \mathrm{mol} / 1$ were spiked with methyl-amino-antipyrine to a final concentration of $50 \mathrm{mg} / \mathrm{l}$. Results of 


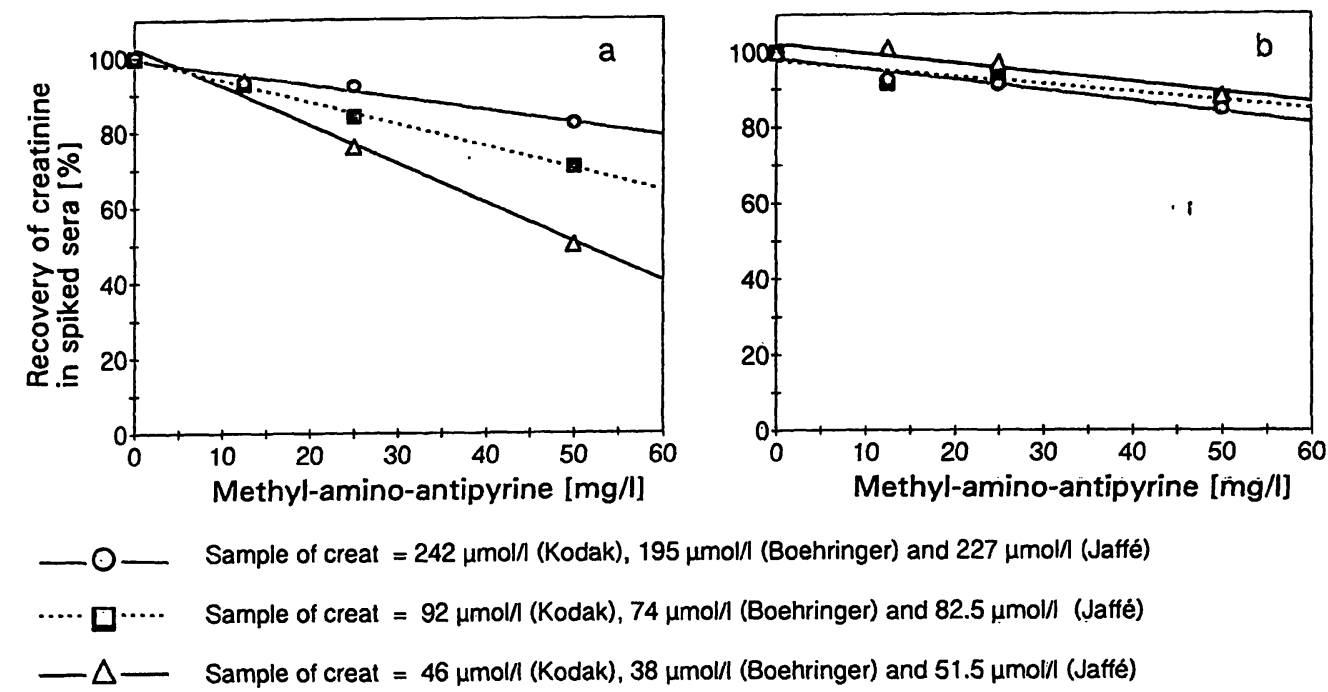

Fig. 4. Influence of various concentrations of methyl-amino-antipyrine on the determination of creatinine in serum with the (a) Kodak and (b) Boehringer methods.

methyl-amino-antipyrine-spiked versus water-spiked sera analysed on the Ektachem 500 are presented in figure 5. This is a confirmation on a large scale of the previous results. The shape of the observed curve shows that low values are more affected by the methyl-amino-antipyrine interference than medium and high values. A linear relation is found for these higher values.

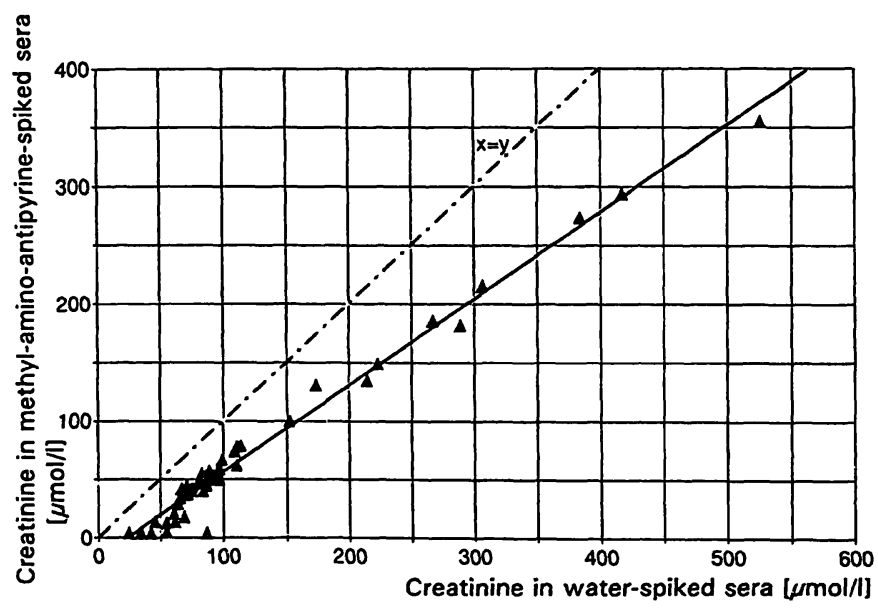

Fig. 5. Creatinine determination with Ektachem in sera spiked with methyl-amino-antipyrine and sera spiked with water (50 samples; methyl-amino-antipyrine spiking $=50$ $\mathrm{mg} / \mathrm{l})$. Correlation curve: $\mathrm{y}=-17.3+0.74 \mathrm{x} ; \mathrm{r}=0.99$

\section{Discussion}

This study demonstrates the importance of considering the relevant in vivo drug and/or metabolites at their usual concentrations.

From an analytical point of view we can say that methyl-amino-antipyrine, the main metabolite of me- tamizol, causes significant interference with the enzymatic determination of creatinine in serum samples. As other metabolites and analogous compounds do not display such a behaviour at the same concentration, this interference seems to be strongly related to the structure of the molecule. Among the four enzymes ${ }^{1}$ ) used in each of the Ektachem and Boehringer methodologies, three are identical. It is therefore difficult to establish which of the three enzymes is effectively inhibited by methyl-amino-antipyrine.

In order to foresee the same action from similar drugs, we asked the Darc $^{\circledR}$ database, giving methyl-aminoantipyrine as the model compound. No proposed structure included used drugs or metabolites.

The interference of methyl-amino-antipyrine with the enzymatic determination of creatinine in serum is clearly clinically relevant in the range of normal and low pathological serum concentrations. The true value is underestimated from $25 \%$ to $75 \%$. It not only influences the interpretation of the serum creatinine per se, but definitely affects the predictive performance of equations that estimate creatinine clearances.

Based on the elimination of methyl-amino-antipyrine in normal subjects (3), it seems therefore reasonable to observe a 3 day stoppage of metamizol treatment before obtaining a reliable serum creatinine concentration with an enzymatic methodology.

\footnotetext{
1) Enzymes:

Creatine amidinohydrolase (EC 3.5.3.3)

Creatinine amidohydrolase (EC 3.5 .2 .10 )

Peroxidase (EC 1.11.1.7)

Sarcosine oxidase (EC 1.5.3.1)
} 


\section{References}

1. Gascon, N., Martinez-Bru, C., Marquez, M., Mercé, J. \& Cortés, M. (1992) Interférence du dipyrone dans la détermination enzymatique de la créatinine avec un Kodak Ektachem 700. Ann. Biol. Clin. 50, 355.

2. Damm, D. (1989) Simultaneous determination of main metabolites of dipyrone by high-pressure liquid chromatography. Drug. Res. 39, 1415-1417.

3. Meyer, B. H. (1988) Absolute bioavailability of single doses of Novalgin tablets and drops versus intravenous injection. Hoechst's Internal Data.

4. Volz, M. (1991) Hoechst AG, Personnel communications.

5. Kodak Ektachem (1987) Test Methodologies. User Manual.
6. Mauck, J. C., Mauck, L., Novros, J. \& Norton, G. E. (1986) Development of a single-slide Kodak Ektachem thin film assay for serum and urine creatinine. Clin. Chem. 32, 11971198.

7. Kodak Ektachem 500 Analyser (1989) Reference Manual.

8. Ambrose, R. T., Ketchum, D. F. \& Smith, J. W. (1983) Creatinine determined by "high performance" liquid chromatography. Clin. Chem. 29, 256-259.

9. Itoh, S., Tanake, K., Furuichi, A., Suzaka, T., Kubo, K., Yamazaki, M. \& Kamada, A. (1984) Ion-pair high-performance liquid chromatographic analysis of sulpyrine and its metabolites in rabbit plasma. Chem. Pharm. Bull. 32, 31943198.

Dr M.-A. Bagnoud

ICHV, Av du Gd Champsec

CP 510

CH-1951 Sion

Switzerland 


$$
\text { • }
$$

